\title{
Comparative Election Forecasting: Further Insights from Synthetic Models
}

Electoral Studies, accepted

\begin{abstract}
As an enterprise, election forecasting has spread and grown. Initial work began in the 1980s in the United States, eventually travelling to Western Europe, where it finds a current outlet in the most of the region's democracies. However, that work has been confined to traditional approaches - statistical modeling or poll-watching. We import a new approach, which we call synthetic modeling. These forecasts come from hybrid models blending structural knowledge with contemporary public opinion, to generate ongoing nowcasts of Western European national contests, from six months prior to Election Day itself. These test results, based on election pools from Germany, the United Kingdom, and France, encourage similar research on other European electorates.
\end{abstract}




\section{INTRODUCTION}

Election forecasting models are generally applicable and should therefore be implemented in a variety of democracies. For developing comparative election forecasting models, we build on leading scientific approaches in the field. [For general reviews, see Lewis-Beck and Tien (2012), Stegmaier and Norpoth (2013)]. Recent applications come from the United States, where the 2012 US presidential election was subject to an unprecedented amount of systematic forecasting work. [See Campbell (2012), who offered a pre-election review of presidential forecasts; also, see Lewis-Beck and Stegmaier (2014a), and their edited symposium of pedagogical forecasting papers on that contest; further, see Linzer and Lewis-Beck (2015), and their edited collection of high-tech articles on the dynamics of forecasting that race.] The dominant scientific approaches for that election were executed by three groups of forecasters: structuralists, aggregators, and synthesizers (Lewis-Beck and Stegmaier, 2014a).

These approaches can be delineated by their application of theory, data, and time. Below, we outline each, and then consider their application to elections in other democratic nations, namely those of Western Europe. After reviewing the relevant work to date, we pursue the development of synthetic models for forecasting national elections in Germany, the United Kingdom, and France. In the comparative spirit, we impose one overarching theoretical structure - a political economy one - across these three systems. As we shall see, the innovation of synthetic models, which combine key elements of the structuralist and aggregator methods, provides a promising development in election prediction on that side of the Atlantic. 


\section{WAYS OF ELECTION FORECASTING: STRUCTURALISTS, AGGREGATORS, SYNTHESIZERS}

The front-running scientific approach to election forecasting has been structural modeling, a method fully advanced in the United States case. For the 2012 presidential race, examples appear in Abramowitz (2012), Campbell (2012) and Holbrook (2012). Such efforts offer a theoretical model of the election outcome, usually beginning with a core political economy explanation, e.g., vote $=f$ (presidential popularity, economic growth). [For a current review of vote and popularity functions, see Lewis-Beck and Stegmaier (2013).] In this work, the unit of analysis tends to be the nation, the estimation ordinary least squares (OLS) on single equations. Further, estimation is static, rather than dynamic, resulting in a unique final forecast.

An emergent rival approach to structural modeling, which draws on the public opinion polling tradition, is aggregation. For the 2012 presidential race, see the examples and discussions by Blumenthal (2014), Jackman (2014), and Traugott (2014). Such analysts aggregate vote intention in opinion polls, combining voter preferences (in percentages) over a number of multiple polls. Distinct from the structuralists, the aggregators offer no theory of the vote. Moreover, the unit of analysis is usually the nation. Finally, forecasting is dynamic, with repeated estimates across the campaign.

Synthesizers, in contrast to the foregoing methodologies, offer something new. For examples, see the work of Erikson and Wlezien (2014), Linzer (2013) or Silver 
(2012). These modelers borrow from the structuralists and the aggregators. They start with a political economy theory of the vote, and add to it aggregated and updated polling preferences. The data are analyzed at the national level or the state level. Further, the analysis of synthesizers may include multiple equations, and may be Bayesian. Finally, their forecasts are updated, with multiple estimates over the campaign. Such models join election theory with the strengths of aggregation and dynamic updating, and are the emphasis of our European efforts (see also Lewis-Beck and Dassonneville (2015)).

The forecasting art in Europe is expanding rapidly. And overall, we can say that structural models dominate the scene. For example, see Dassonneville and Hooghe (2012) on Belgium; Magalhães, Aguiar-Conraria and Lewis-Beck (2012) on Spain; Nadeau, Lewis-Beck and Bélanger (2010) on France; Whiteley (2005) on the United Kingdom; Norpoth and Gschwend $(2010,2013)$ on Germany. These efforts tend to be based on a political economic theory of voting. Also, the modeling is single-country, single-equation OLS work. Estimation is static, with one unique forecast issued. The unit of analysis is usually, but not always, the nation.

Aggregation, where polls are combined, and systematically used to forecast, is almost non-existent in Europe. For a useful exception, see Jennings and Wlezien (2015), who amass over 23,000 polls from 41 countries, and examine how well they predict vote outcome. Additionally, using individual house polls on vote intention to forecast elections represents a long-standing tradition, especially within the media. [In particular see the plentiful work on the United Kingdom, dating back to the 1980s e.g., Sanders, Hugh and Marsh (1987).] The situation worsens with regard to the synthesizers. We know of no examples of synthetic models on a general national election in Europe, with 
the exception of our own work (Lewis-Beck and Dassonneville, 2015), on which we build further here.

\section{BUILDING SYNTHETIC MODELS FOR ELECTIONS IN EUROPE}

For building a synthetic model, we combine a sound structural model with a sound polling model. Combined, they form a hybrid that can forecast national election outcomes accurately across a sample of European democracies. That hybrid will contain an explicitly theoretical and an explicitly nontheoretical component; therefore, we label it a "synthetic" model. First, the proposed structural model, with its political economy core, we write as follows:

$$
\text { Vote }_{\mathrm{t}}=f(\text { Economy, Government Support }) \text {. }
$$

Second, the polling model, which predicts the incumbent vote share as a function of vote intention, we write as follows:

$$
\text { Vote } \mathrm{t}=f\left(\text { Polls }_{\mathrm{t}-\mathrm{x}}\right)
$$

The synthetic model combines into one these two models. It begins with the longterm fixed effects from electoral theory, as captured in the structural model. Then, it adds to that the short-term effects induced by other forces, as represented by the polling model, using the latest available information on Vote Intention $\left(\mathrm{VI}_{\mathrm{t}-\mathrm{x}}\right)$ to predict the vote. The 
addition of this $\mathrm{VI}_{\mathrm{t}-\mathrm{x}}$ term to the specification can be justified as a solution to a missing variables problem. That is, other variables that help predict the vote may occur after the structural forecast; or, they may simply not be measurable directly at any time point. To the extent $\mathrm{VI}_{\mathrm{t}-\mathrm{x}}$ helps reducing error, this should become evident over time.

The synthetic model thus makes a blend of theory and empirics. And, it takes a dynamic form, with progressive re-estimations as the election becomes closer. With reference to the 2012 US presidential election forecasting work, then, it is most similar to the superlative efforts of Erikson and Wlezien (2013). We follow a similar estimation strategy, i.e., a non-Bayesian one. For the best in Bayesian models, applied to US presidential election forecasting, see Linzer's (2013) paper on the 2008 election, and his VOTAMATIC blog for the 2012 election.

The basic idea behind the synthetic model is that it operates like contemporary weather forecasting models (see Lewis-Beck and Stegmaier (2014b). The fundamental variables governing the atmosphere first generate an event forecast, for example a rainstorm. Then that forecast is checked against additional, incoming information, as the storm pattern is tracked. The initial forecast - based on long-term theories - is hence updated, and modified regularly by ever more current forecasts. The process thereby becomes dynamic and these dynamic forecasts become more accurate as the range is shorter. In terms of election forecasting, the fundamentals determining the behavior of the electorate are analyzed to predict an election first. But as Election Day draws near, more information on vote intentions becomes available, and this information is subsequently used to update the initial event forecast. 


\section{SYNTHETIC MODEL FORECASTS IN PRACTICE}

On each of the European countries under study, we first estimate the structural model (at t-6). Then, we estimate the polling model by simply taking the latest single poll that is

published. If there is more than one poll at the same time point, we simply average them. Finally, we make a combined, single equation synthetic model forecast, with new synthetic forecasts at each time a new vote intention poll is out. This dynamic assumes that while the structural model is fixed (at $\mathrm{t}-6$ ), the polling model is updated as polls are published. This formulation allows a new "nowcast" of the election result with each new poll (Lewis-Beck and Tien, 2013). Each of the vote intention polls thus offers a correction to the prediction of the structural part. The idea of a correction stems from the fact that vote intention polls help solving the omitted variables problem. Vote intentions can therefore serve as a proxy for the variables that we cannot include in a parsimonious structural model. In this article, we look at three large, advanced democracies of Western Europe: Germany (1980-2013), the United Kingdom (1959-2010), and France (19652012).

GERMANY

We begin with the German case, first estimating the structural model and its out-ofsample forecast for the most recent election. [For recent structural forecasting work on German elections, see Jérôme, Jérôme-Speziari and Lewis-Beck (2013); Norpoth and Gschwend (2013)]. Then, we carry out estimations from the polling model. Finally, we 
estimate the synthetic model, and its nowcasts from t-6 to Election Day. At the end of the section, we evaluate model performance.

\section{a. Structural model}

As a first step, we estimate a structural model fitting German election results over time. The form is a basic political economy model, with an economic indicator (in this case GDP growth) and a political indicator (government approval) The dependent variable is the combined vote share of the incumbent parties. ${ }^{1}$

$$
\mathrm{V}=\beta_{0}+\beta_{1} \mathrm{GDP}_{\mathrm{t}-6}+\beta_{2} \text { Government approval }_{\mathrm{t}-6}+\varepsilon
$$

where $\mathrm{V}$ is the combined vote share of the incumbent parties: GDP is the GDP growth rate (seasonally adjusted and compared to the same quarter in the previous year) in the second quarter before the election quarter; Government approval is the mean value of satisfaction with the government's performance (0-10) in the FGW-survey 6 months before the election (see the Appendix for data sources).

Estimating the equation (OLS) for German Bundestag elections from 1980 to 2009 yields the following:

$$
\mathrm{V}=27.157^{* *}+1.701^{* *} \mathrm{GDP}_{\mathrm{t}-6}+3.638^{*} \text { Government approval }_{\mathrm{t}-6}
$$

\footnotetext{
${ }^{1}$. We follow Norpoth and Gschwend (2010) by only taking into consideration the chancellor's party in case of a Grand Coalition and by only treating SPD as an incumbent party for the 1983 election.
} 


$$
\begin{aligned}
& \mathrm{N}=8(1980-2009) \quad \text { Adj. } \mathrm{R}^{2}=0.822 \\
& \mathrm{RMSE}=2.994 \quad \mathrm{DW}=3.031 \\
& { }^{* * *}=\text { significant at } .001,{ }^{* *}=\text { significant at } .01,{ }^{*}=\text { significant at } .05 \text {. }
\end{aligned}
$$

To make an out-of-sample forecast for the next Bundestag election, we simply plug into the prediction equation the appropriate values for GDP growth and Governmental Popularity, at a six months lag, as follows:

$$
\begin{aligned}
V & =27.157+1.701(-0.30)+3.638(5.55) \\
& =46.8 \%
\end{aligned}
$$

The actual incumbent result $=46.3 \%$, for an absolute forecasting error of 0.5 percentage points.

\section{b. Polls model and forecast of the 2013 Bundestag Election}

The assumption of the polls model is simply that vote intention polls predict the election result. We hence assume that the vote share is a function of the public's vote intentions, as observable in polls. These polls come with some error, however, as sampling errors as well as systematic polling house errors are inevitable.

$$
\mathrm{V}_{\mathrm{t}}=f\left(\text { Vote intention }_{\mathrm{t}-\mathrm{x}}+\varepsilon\right)
$$

where $\mathrm{V}_{\mathrm{t}}$ is the combined vote share of the incumbent parties and Vote intention ${ }_{\mathrm{t}-\mathrm{x}}$ is the combined vote share incumbent parties obtain in a pre-electoral poll. 
In Figure 1, we see the prediction error from the Vote Intention Model over time. First, for each poll that was published in the run up to Election Day, the error from the real election result was calculated. The regression line reported in Figure 1 is the result of regressing these errors on time (measured as days to the election). As we can see, the error steadily decreases as the poll estimates moves closer to the day of the election. On the eve of the election, the error is reduced to just over $1 \%$.

\section{[FIGURE 1 ABOUT HERE]}

\section{c. Synthetic model}

The synthetic model incorporates the polling model information, generating a nowcast from t-6 months to Election Day. Dynamic weights are used to take into account that the importance of both information sources can vary over time. ${ }^{2}$ Polls are assumed to become more accurate moving forward - as was also apparent from looking at Figure 1 - and therefore are given increasing weight over time. Thus, the weights are adjusted monthly, in the manner shown in Table 1.

\section{[TABLE 1 ABOUT HERE]}

The weights applied are dynamic but fixed, and based on the assumption that the polling part becomes more important over time. A number of reasons can be given for this choice. First, except for the structural model - which is based on an analysis of historical

\footnotetext{
${ }^{2}$. Note that giving both elements a constant equal weight (each part is multiplied by 0.5 ) does not substantially change our conclusions. Results available from the authors upon request.
} 
data, the forecasts are limited to a single election each time. Consequently, there is no variation in the dependent variable and we cannot actually regress vote intentions or the combined model on the outcome of the model to determine the impact of both parts of the synthetic model. What we do present, instead, is how different approaches (the historical structural model, vote intention polls and a combination of both) to forecasting the most recent election perform in terms of prediction error and how these errors evolve over time. Second, one way to allow the data to determine the weights of the structural and polling parts would be to take into account the ratio of the errors of the polling and structural models at a particular point in time. This, however, would imply relying on the election outcome for calculating which part of the synthetic model should receive most weight. Such an approach would self-evidently imply that we are no longer developing a general model that can be applied to forecasting an election outcome before Election Day. A third approach to estimating single-level models would be to rely on historical vote intention-data, collected in the context of different elections as well. This approach, however, is data intensive and requires the availability of decades long vote intention data series. Furthermore, implementing this method for a limited number of European countries for which the data to do so are at hand, indicates more error and a weaker fit compared to structural models (Lewis-Beck and Dassonneville, 2015). Most likely, this is due to the fact that as one goes further back in time, polling data are more scarce and hence more sensitive to outliers.

Incorporating this dynamic of weighted structural and polling parts, yields this overall forecasting equation for the synthetic model, 
$\mathrm{V}=\beta_{0}+$ Structural weight $*\left[\beta_{1}\right.$ GDP $+\beta_{2}$ Government approval $]+$ Polling weight $*[$ Vote intention] $+\varepsilon$

In words, the equation offers a polling correction to the structural forecasts, rendering the structural model dynamic. We can now compare its performance to that of the structural or polling models taken separately. In Figure 2, the absolute forecasting errors of each of the different model forecasts is regressed on time (days to the Election Day). We observe, on the one hand, that the structural model alone generates a constant (and low) error over time. On the other hand, the polling model alone generates a declining (but always higher) error over time. The synthetic model, however, improves on both, offering steadily decreasing error that quickly betters the error of the structural model by itself. Indeed, by about five months before Election Day, it surpasses the accuracy of the polling model. The Synthetic Model steadily improves over time, until by Election Day there is virtually no forecasting error. In sum, for the German case the synthetic model clearly shows gains over either of the other approaches taken alone.

[FIGURE 2 ABOUT HERE]

THE UNITED KINGDOM

\section{a. Structural model}

Election forecasting in the United Kingdom has recently been the focus of considerable attention. [See, for example, the edited collection of papers by Gibson and Lewis-Beck 
(2011)]. Different foundational structural models are possible. As a heuristic, we estimate a structural model of the same form as the model presented for Germany, thus using GDP growth rates ${ }^{3}$ and government approval data as predictors:

$$
\mathrm{V}=\beta_{0}+\beta_{1} \mathrm{GDP}_{\mathrm{t}-6}+\beta_{2} \text { Government approval }_{\mathrm{t}-6}+\varepsilon
$$

where $\mathrm{V}$ is the combined vote share of the incumbent parties; GDP is the GDP growth rate (seasonally adjusted and compared to the same quarter in the previous year) in the second quarter before the election quarter; Government approval is Gallup and IPSOS Mori government approval data (\% satisfied with the way the government is running the country) six months before the election (see Appendix for data sources). Estimating this structural model, for general elections in the United Kingdom from 1959 to 2005, gives us the following result:

$$
\begin{aligned}
& \mathrm{V}=26.403^{* *}-0.361^{*} \mathrm{GDP}_{\mathrm{t}-6}+0.370^{*} \text { Government approval } \mathrm{t}-6 \\
& \quad(5.395) \quad(0.493) \quad(0.137) \\
& \mathrm{N}=13(1959-2005) \quad \text { Adj. } \mathrm{R}^{2}=0.317 \\
& \mathrm{RMSE}=4.152 \quad \mathrm{DW}=1.699 \\
& { }^{* * *}=\text { significant at } .001,{ }^{* * *}=\text { significant at } .01,{ }^{*}=\text { significant at } .05 .
\end{aligned}
$$

Next, we use these estimations to make an out-of-sample forecast of the 2010 general election. To this end, we add the structural information (GDP growth rate and government approval data) into the structural model, as follows:

\footnotetext{
${ }^{3}$. It has to be noted, however, that in line with the findings of Lewis-Beck, Nadeau and Bélanger (2004), a structural model with inflation rates instead of GDP growth rates fits the data better.
} 
$\mathrm{V}=26.403+0.361(-2.47)+0.370(25)$

$=34.8 \%$.

The actual 2010 incumbent result $=29.0 \%$, giving an absolute forecasting error of 5.8 percentage points.

b. Polls model and forecast of 2010 UK general election

As with the German case, the polls model is as follows,

$\mathrm{V}_{\mathrm{t}}=f\left(\right.$ Vote intention $\left._{\mathrm{t}-\mathrm{x}}+\varepsilon\right)$

Where $V_{t}$ is the combined vote share of the incumbent parties and Vote intention is the combined vote share incumbent parties obtain in pre-electoral polls, at a given point in time.

In Figure 3, we show the error of that prediction from polled vote intention over time. We observe that that prediction line remains virtually flat as it moves toward Election Day, yielding a forecast error of just over 2 percentage points.

[FIGURE 3 ABOUT HERE]

\section{c. Synthetic model}

The Synthetic Model for the United Kingdom case can be expressed as follows, 
$\mathrm{V}=\beta_{0}+$ Structural weight $*\left[\beta_{1} \mathrm{GDP}+\beta_{2}\right.$ Government approval $]+$ Polling weight $*$ [Vote intention] $+\varepsilon$

In Figure 4, we see the prediction lines for the three separate models. Regressing each of the forecasts on time, the structural model is constant - with its six months lead while the polling and synthetic models are updated as new polls are published. The structural model does poorly, with a consistently high error. The vote intention model clearly does better, but offers no reduction in error over time. In contrast to both, the synthetic model shows a steady decline in prediction error as Election Day approaches, and by election eve is only about one percentage point off.

[FIGURE 4 ABOUT HERE]

\section{FRANCE}

\section{a. Structural model}

The structural model for French presidential elections takes inspiration for a family of political economy models. Most recently, see Nadeau et al. (2010). The form here parallels exactly the foregoing models, with presidential approval instead of government approval data, reading thusly:

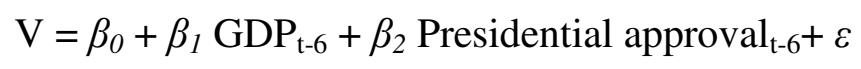


where $\mathrm{V}$ is the $1^{\text {st }}$ round vote share of the presidential candidate of the incumbent party, GDP is the GDP growth rate (seasonally adjusted and compared to the same quarter in the previous year) in the second quarter before the election quarter, and Presidential approval is the percentage of respondents stating to be satisfied with how the president is doing his job in the IFOP-survey 6 months before the election (see Appendix for data sources). Below are the OLS estimates for estimating this model on all French presidential elections between 1965 and 2007:

$$
\begin{aligned}
& \mathrm{V}=18.666+2.988 \mathrm{GDP}+0.066 \text { Presidential approval } \\
& \text { (14.189) (1.185) } \\
& \mathrm{N}=8 \text { (1965-2007) } \quad \text { Adj. } \mathrm{R}^{2}=0.481 \\
& \mathrm{RMSE}=6.424 \quad \mathrm{DW}=1.816
\end{aligned}
$$

While all estimated effects are in expected directions, none of them reaches a conventional level of statistical significance because of collinearity. However, the overall model fit of the French structural model suggests almost half of the variance can be accounted for. Thus, we go on to employ the model to make a 2012 forecast.

Next, we rely on this structural model to produce an out-of-sample forecast for the 2012 French presidential election. We hence plug in the structural information (GDP and presidential approval, each with a six months lag) in the equation of the structural model:

$$
\begin{aligned}
V & =18.666+2.988(1.5)+0.066(31) \\
& =25.2 \%
\end{aligned}
$$


The actual 2012 incumbent presidential candidate result $=27.2 \%$, which implies an absolute forecasting error of 2 percentage points.

\section{b. Poll model and forecast of 2012 French presidential election}

As with the earlier cases of Germany and the United Kingdom, the polling model reads as follows:

$\mathrm{V}_{\mathrm{t}}=f\left(\right.$ Vote intention $\left._{\mathrm{t}-\mathrm{x}}+\varepsilon\right)$

where $\mathrm{V}$ is the combined vote share of the incumbent parties and Vote intention is the vote share the presidential candidate of the incumbent party obtains in pre-election poll(s), at a given point in time.

As can be seen in Figure 5, the forecast from the polls alone steadily improves over time, falling from an error of about 2.5 percentage points five months out, to about one percentage point a month before the election.

[FIGURE 5 ABOUT HERE]

\section{c. Synthetic model}

Next, the structural model is combined with the polls, to generate a synthetic model. As we did for Germany and the United Kingdom as well, the structural and polling parts are 
weighted to take into account that polls become more accurate predictors of the election result over time.

$\mathrm{V}=\beta_{0}+$ Structural weight $*\left[\beta_{1}\right.$ GDP $+\beta_{2}$ Presidential approval $]+$ Polling weight $*\left[\beta_{3}\right.$ Vote intention] $+\varepsilon$

As can be seen in Figure 6, where we regress each of the model's predictions on the number of days until the election, the structural model works better than the polling model until about 4 months out, after which the Polling model does better. However, the synthetic model does better than either, from about three months out, when the error drops below two percentage points, and continues to drop.

[FIGURE 6 ABOUT HERE]

\section{SUMMARY AND CONCLUSION}

With this article, we wish to advance election forecasting theoretically and methodologically further building on our previous work examining synthetic forecasting models for European democracies (Lewis-Beck and Dassonneville, 2015). With respect to theory, we put forward a political economy core model, defined structurally by the presence of key macro-economic and macro-political indicators, namely economic performance and government satisfaction. We test this structural model across a sample of leading Western European democracies, and find that it affords a modicum of predictive power, and at a substantial lead (of 6 months before the election). However, 
this structural model, by itself, leaves behind too much forecasting error. Further, it offers only static, rather than dynamic, forecasts.

Therefore, we supplement these structural models with polling models, based on vote intention. We show that, with the addition of vote intention measures, so forming what we call a synthetic model, considerable gains in accuracy can be made in the forecasting of these Western European elections. However, it is worth underlining that both components of the synthetic model - the structural part and the vote intention part are important. Sometimes the structural model seems to add more, as in the German case, while at other times the vote intention part seems to add more, as in the United Kingdom case. Or, the contributions may appear mixed within one particular electoral system, as in the French case where it appears that the structural component dominated early, the vote intention component later. Be that as may be, the essential point remains: the synthetic model, with its combination of methods, works better than either of these leading methods taken alone.

What is the next step? Clearly, our work takes only a first step. The synthetic model needs to be tested against other democratic electorates. That is easier said than done, if our experience at trying to amass the necessary data serves as a guide. We explored other Western European democracies, e.g., Norway, The Netherlands, Ireland, but could not amass satisfactory data sets. Of course, these difficulties multiply, when other democratic nations, beyond Europe, are considered. Another way to expand the number of observations would involve lower the level of analysis, from the nation to the district. For instance, in the French case, analysis might go forward with region as the case unit, rather than the nation as a whole. But that strategy carries its own difficulties, 
in particular the lack of proper measures of government support, not to mention the technical issue of spatial autocorrelation that would demand correction. Nevertheless, these obstacles cannot be allowed to stand indefinitely. We must make the effort to apply synthetic models to the elections, including second-order elections, of other European democracies.

\section{ACKNOWLEDGEMENT}

Ruth Dassonneville thanks the Research Foundation Flanders (FWO) for its generous support. We would also like to thank Chris Wlezien for his insightful comments and Guy Whitten for organizing an excellent conference. Finally, we would like to acknowledge the anonymous reviewer(s).

\section{REFERENCES}

Abramowitz, A., 2012. Forecasting in a polarized era: The time for change model and the 2012 presidential election. PS: Political Science \& Politics 45 (4), 618-619.

Blumenthal, M., 2014. Polls, forecasts, aggregators. PS: Political Science \& Politics 47 (2), 297-300.

Butler, D., Butler, G., 2000. Twentieth-century British political facts, 1900-2000. Macmillan, Basingstoke.

Campbell, J.E., 2012. Forecasting the 2012 American national elections. PS: Political Science \& Politics 45 (4), 610-613. 
Dassonneville, R., Hooghe, M., 2012. Election forecasting under opaque conditions: A model for Francophone Belgium, 1981-2010. International Journal of Forecasting 28 (4), 777-788.

Erikson, R.S., Wlezien, C., 2013. Forecasting with leading indicators and the polls in 2012. PS: Political Science \& Politics 46 (1), 38-39.

Erikson, R.S., Wlezien, C., 2014. Forecasting US Presidential Elections Using Economic and Nonecomomic Fundamentals. PS: Political Science \& Politics 47 (2), 313-316.

Federal Statistical Office Germany (2014). GDP quarterly national accounts.

Forschungsgruppe Wahlen, Mannheim (2014): Partial Cumulation of Politbarometers West 1977-2012. GESIS Data Archive, Cologne. ZA2391 Data file Version 4.0.0, doi:10.4232/1.11872

$\begin{array}{lllll}\text { Forschungsgruppe } & \text { Wahlen } & \text { (2014). } & \text { Politik } & \text { II. }\end{array}$ http://www.forschungsgruppe.de/Umfragen/Politbarometer/Langzeitentwicklung__Themen_im_Ueberblick/Politik_II/ (July 9, 2014).

Gibson, R., Lewis-Beck, M.S., 2011. Methodologies of election forecasting: Calling the 2010 UK “hung parliament”. Electoral Studies 30 (2), 247-249.

Holbrook, T.M., 2012. Incumbency, national conditions, and the 2012 presidential election. PS: Political Science \& Politics 45 (4), 640-643.

IFOP monthly barometer, 2014. Satisfaction with performance of the president. www.ifop.fr (July 9, 2014).

Jackman, S., 2014. The predictive power of uniform swing. PS: Political Science \& Politics 47 (2), 317-321. 
Jérôme, B., Jérôme-Speziari, V., Lewis-Beck, M.S., 2013. A political-economy forecast for the 2013 German elections: Who to rule with Angela Merkel? PS: Political Science \& Politics 46 (3), 479-480.

Jennings, W., Wlezien, C., 2015. The timeline of election campaigns: A comparative perspective. American Journal of Political Science, forthcoming.

Lewis-Beck, M.S., Dassonneville, R., 2015. Forecasting elections in Europe: Synthetic models. Research and Politics, 1(1), 1-11. DOI: 10.1177/2053168014565128.

Lewis-Beck, M.S., Nadeau, R., Bélanger, É., 2004. General Election Forecasts in the United Kingdom: A Political Economy Model. Electoral Studies 23 (2), 279-290.

Lewis-Beck, M.S., Stegmaier, M., 2013. The VP-function revisited: A survey of the literature on vote and popularity functions after over 40 years. Public Choice 157 (3/4), 367-385.

Lewis-Beck, M.S., Stegmaier, M., 2014a. Forecasting the 2012 United States presidential election: A symposium. PS: Political Science \& Politics forthcoming.

Lewis-Beck, M.S., Stegmaier, M., 2014b. Forecasts: After Richardson. PS: Political Science \& Politics forthcoming.

Lewis-Beck, M.S., Tien, C., 2012. Election forecasting for turbulent times. PS: Political Science \& Politics 45 (4), 625-629.

Lewis-Beck, M.S., Tien C., 2013. Proxy forecasts: A working strategy. PS: Political Science \& Politics 46 (1), 39-40.

Linzer, D.A., 2012. VOTAMATIC: Forecasts and Polling Analysis for the 2012 Presidetnial Election. votamatic.org (July 9, 2014). 
Linzer, D.A., 2013. Dynamic bayesian forecasting of presidential elections in the States. Journal of the American Statistical Association 108 (201), 124-134.

Linzer, D., Lewis-Beck, M.S., 2015. United States presidential election forecasting, special section. International Journal of Forecasting forthcoming.

Magalhães, P.C., Aguiar-Conraria, L., Lewis-Beck, M.S., 2012. Forecasting Spanish elections. International Journal of Forecasting 28 (4), 769-776.

Nadeau, R., Lewis-Beck, M.S., Bélanger, É., 2010. Electoral forecasting in France: A Multi-equation solution. International Journal of Forecasting 26 (1), 11-18.

Norpoth, H., Gschwend, T., 2010. The chancellor model: Forecasting German elections. International Journal of Forecasting 26 (1), 42-53.

Norpoth, H., Gschwend, T., 2013. Chancellor model picks Merkel in 2013 German election. PS: Political Science \& Politics 46 (3), 481-482.

Pack, M., 2014. Opinion polls spreadsheet. www.markpack.org.uk (July 9, 2014).

Sanders, D., Hugh, W., Marsh, D., 1987. Government popularity and the Falklands war: A reassessment. British Journal of Political Science 17 (3), 281-313.

Silver, N., 2012. FiveThirtyEight's 2012 Forecast. New York Times. http://fivethirtyeight.blogs.nytimes.com/fivethirtyeights-2012-forecast/ (July 9, 2014).

Office for National Statistics, 2014. Inflation. Annual change in retail price index (monthly percentages). www.statistics.gov.uk (July 9, 2014).

Organisation for Economic Co-Operation and Development (OECD), 2014. Quarterly National Accounts: Quarterly growth rates of real GDP, change over pervious quarter. stats.oecd.org/index.aspx?queryid=350 (9 July, 2014). 
Stegmaier, M., Norpoth, H., 2013. Election forecasting. In: Valelly, R. (Ed.), Oxford Bibliographies in Political Science. Oxford University Press, New York.

Traugott, M.W., 2014. Public opinion polls and election forecasts. PS: Political Science \& Politics 47 (2), 342-344.

Wahlen, Wahlrecht und Wahlsysteme, 2014. Sonntagsfrage Bundestagswahl, http://www.wahlrecht.de/umfragen/index.htm (July 9, 2014).

Whiteley, P.F., 2005. Forecasting seats from votes in British general elections. The British Journal of Politics \& International Relations 7 (2), 165-173. 


\section{APPENDIX. DATA SOURCES}

\section{GERMANY}

- Government approval : Data from FGW Politbarometer (1977-2013), question wording is « Sind Sie mit den Leistungen der Bundesregierung aus xxx und xxx eher zufrieden oder eher unzufrieden ? Bitte beschreiben Sie es wieder mit dem Thermometer von plus 5 bis minus 5. 'Plus 5' bedeutet, dass Sie mit den Leistungen der Regierung voll und ganz zufrieden sind. 'Minus 5' bedeutet, dass Sie miet den Leistungen der Regierung volständig unzufrieden sind. Auch hier können Sie mit den Werten dazwischen Ihre Meinung abgestuft sagen. » and was transformed into a 0-10 scale of government approval. For 1983 no information was available at six months before the election, approval rates from seven months before the election month were employed.

- GDP: Data are seasonally adjusted quarterly national GDP accounts (change on the same quarter of the previous year) and come from the Federal Statistical Office Germany (1970-2013).

- Polling data : Vote intention question from Allensbach, Emnid, Forsa, Forschungsgruppe Wahlen, GMS, Infratest dimap and INSA polls for the 2013 elections, as available on www.wahlrecht.de. 


\section{UNITED KINGDOM}

- Government approval data : 1959-1997 Gallup Poll (Butler \& Butler, 2000) ; 2000-2010 IPSOS Mori (www.ipsosmori.com/researchpublications/researcharchive/poll).

- GDP data are seasonally adjusted national GDP accounts (change on the same quarter of the previous year), retrieved from OECD.Stat.

- Polling data : Voting intention questions as compiled by Mark Pack (www.markpack.org.uk/opinion-polls/).

\section{FRANCE}

- Presidential approval data: Percentage of respondents saying to be satisfied with how the president is doing in IFOP monthly barometer (www.ifop.fr.)

- GDP: quarterly national GDP growth rates (seasonally adjusted and compared to same quarter of the previous year), retrieved from the OECD statistics database (stats.oecd.org).

- Polling data: BVA, CSA, Harris interactive, IFOP, IPSOS, LH2, OpinionWay and TNS Sofres vote intention data. Assembled by and retrieved from Jocelyn Evans. 
Figure 1. Predictive power of polls over time (2013 Bundestagelection)

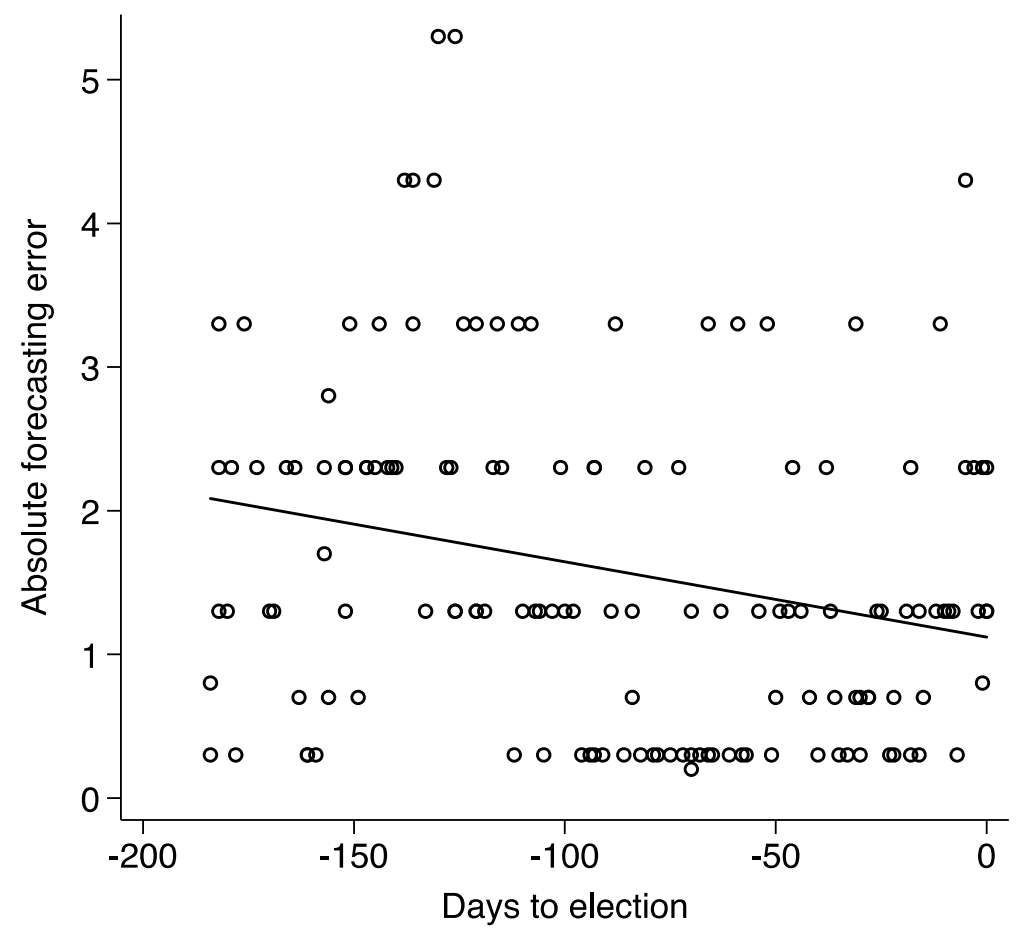

Note: Absolute errors of vote intention polls (compared to 2013 election result). Solid line indicates linear fit of errors regressed on time. 
Table 1. Importance weights over time

\begin{tabular}{lcc}
\hline Time to election & Structural weight & Polling weight \\
\hline-6 months & $6 / 6$ & $0 / 6$ \\
-5 months & $5 / 6$ & $1 / 6$ \\
-4 months & $4 / 6$ & $2 / 6$ \\
-3 months & $3 / 6$ & $3 / 6$ \\
-2 months & $2 / 6$ & $4 / 6$ \\
-1 months & $1 / 6$ & $5 / 6$ \\
\hline
\end{tabular}


Figure 2. Linear model fit of errors over time, Germany.

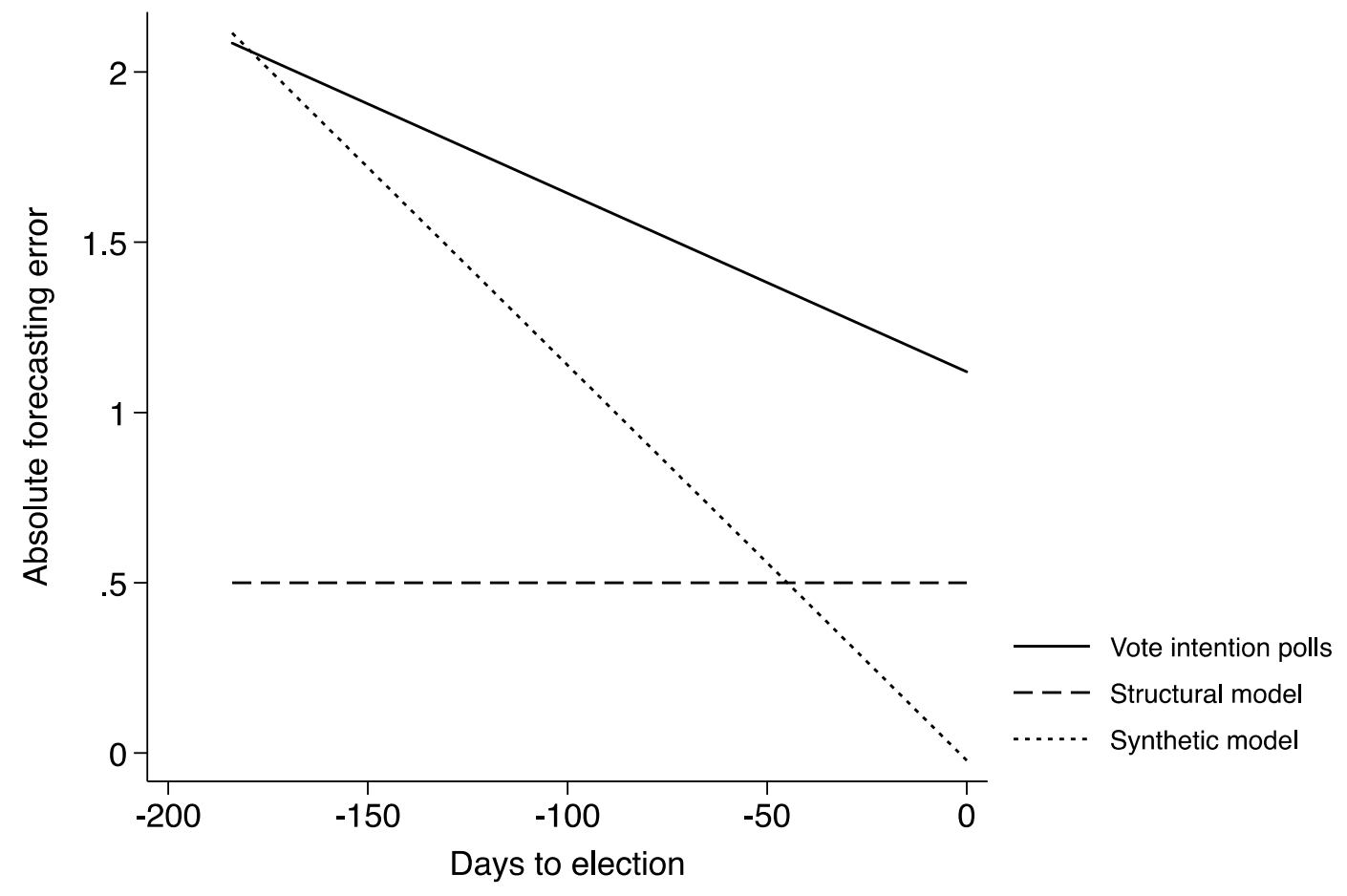


Figure 3. Predictive power of polls over time (2010 UK general election)

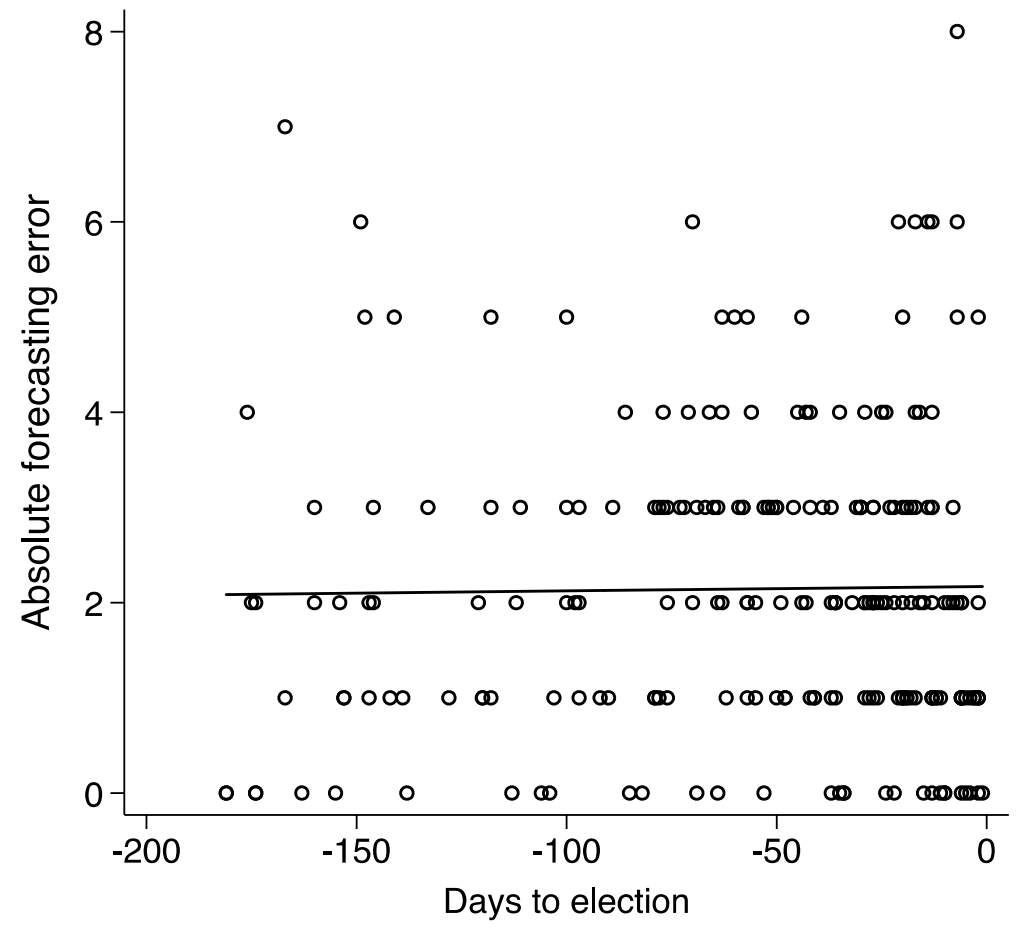

Note: Absolute errors of vote intention polls (compared to 2010 election result). Solid line indicates linear fit of errors regressed on time. 
Figure 4. Linear model fit of errors over time, United Kingdom.

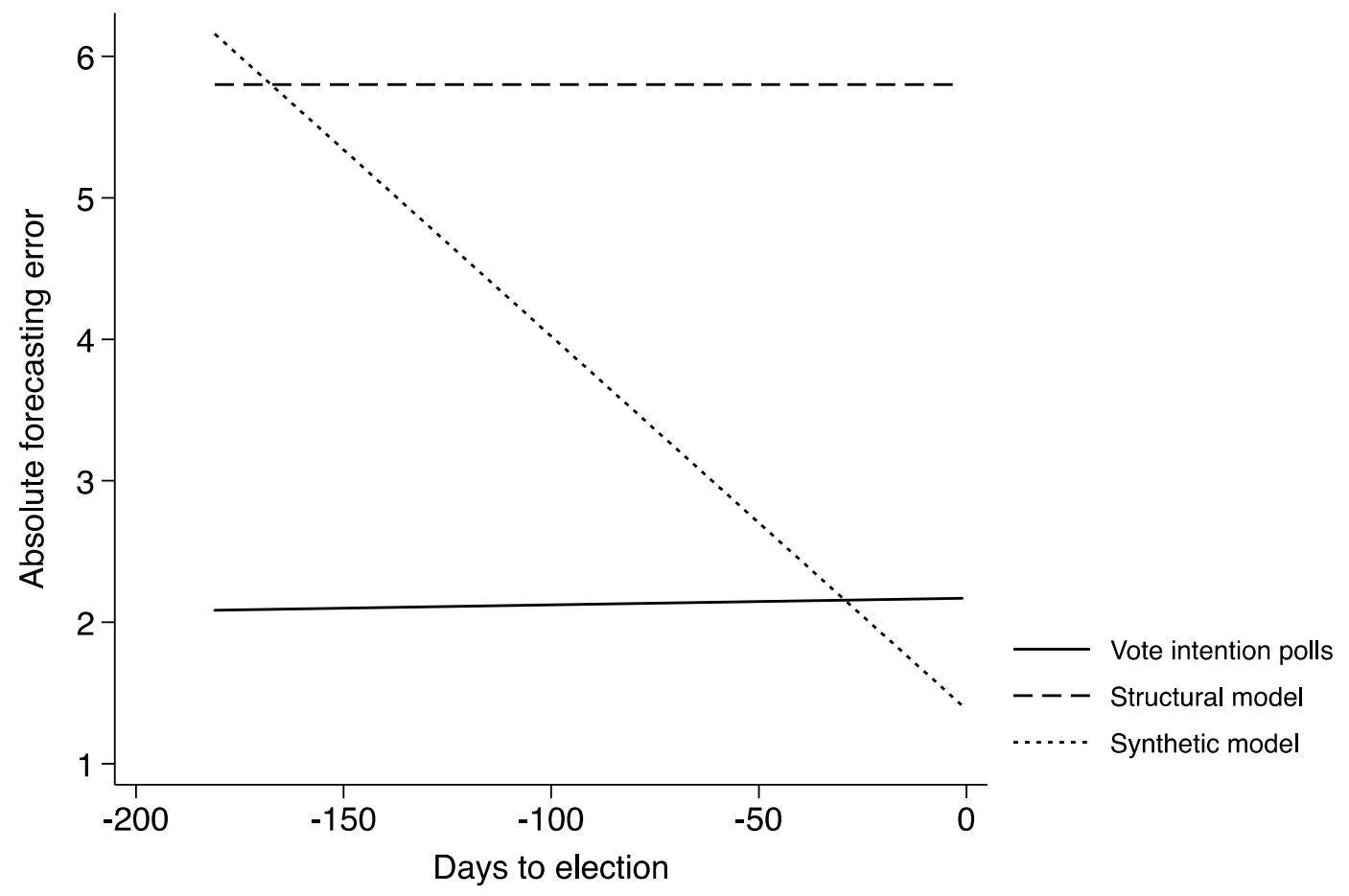


Figure 5. Predictive power of polls over time (2012 Presidential election)

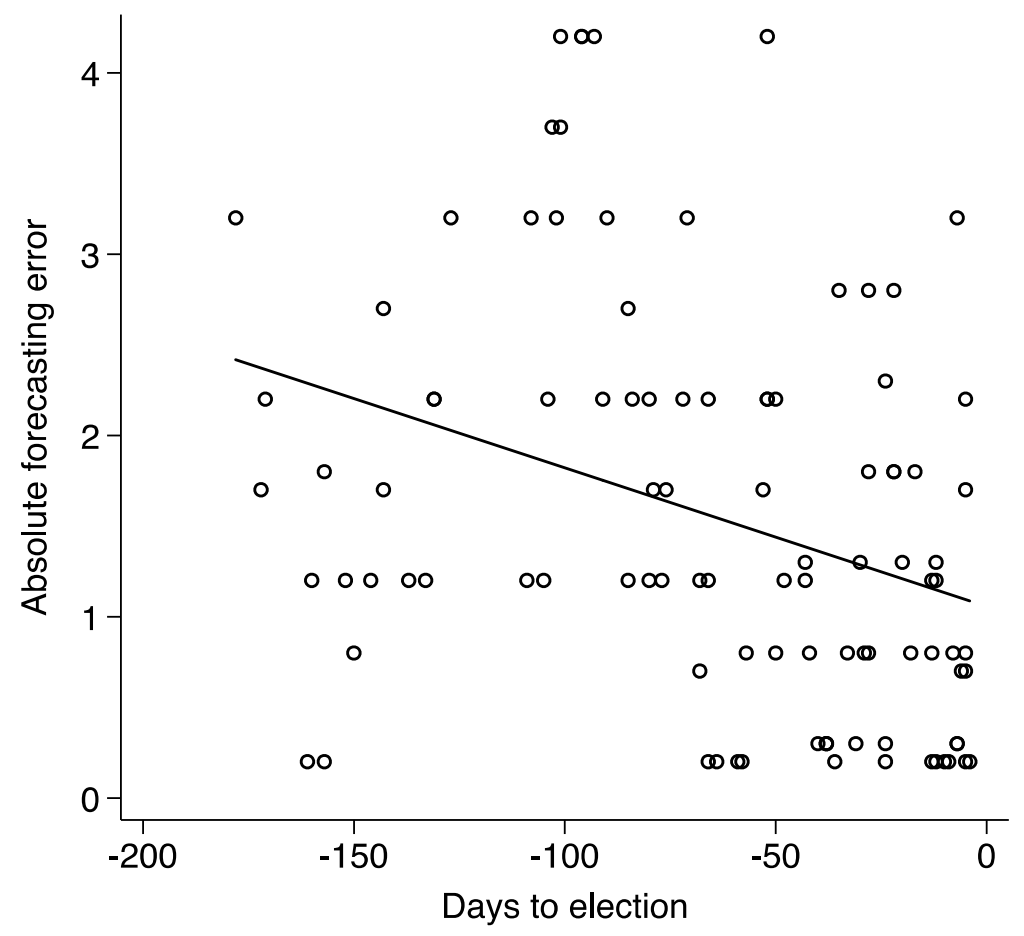

Note: Absolute errors of vote intention polls (compared to 2012 election result). Solid line indicates linear fit of errors regressed on time. 
Figure 6. Linear model fit of errors over time, France.

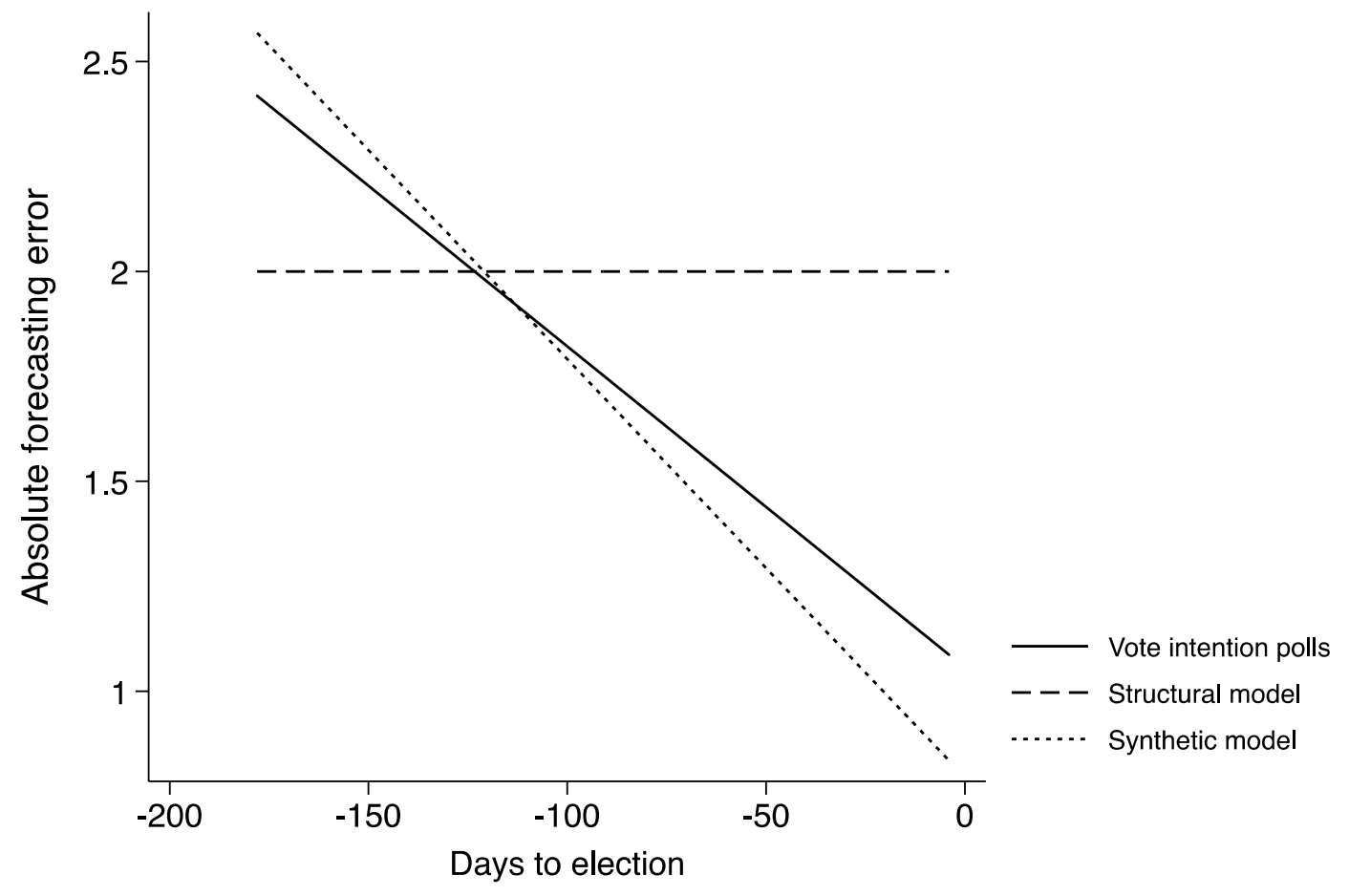

